\title{
THE ONSET AND WITHDRAWAL OF THE RAINY SEASON IN EASTERN THAILAND WITH REGARD TO THE FLOWERING OF MANGOSTEENS AND DURIANS
}

DOI: https://doi.org/10.18509/AGB.2017.01

UDC: 551.553.21:634.65/.67(593)

\author{
Panu Trivej ${ }^{1}$, Bjorn Stevens ${ }^{2}$, Wanitcha Phansri $^{3}$ \\ ${ }^{1}$ Kasetsart University, Thailand \\ ${ }^{2}$ Max-Planck-Institut für Meteologie, Germany \\ ${ }^{3}$ Department of Royal Rainmaking and Agricultural Aviation, Thailand \\ Corresponding author: p2trivej@yahoo.com
}

Submitted: December 2016, Accepted: April 2017, Published: August 2017

\begin{abstract}
In Eastern Thailand, the harvest cycle of mangosteens and durians begins sometime in December, after the end of the rainy season. The fruit plants are sensitive to moisture, and the farmers' main concern is whether their life cycles will begin soon enough to avoid the harmful effects of rain. The dry conditions in October yield an early flowering date, and wet conditions yield a late one. Using statistical analysis, we can infer the October weather condition from the onset date of the rainy season in May. Such knowledge enables a prediction model that allows fruit farmers to plan their crop strategically well ahead of time.
\end{abstract}

Key words: Monsoon, Onset, Withdrawal, Mongosteens, Durians;

\section{Introduction}

Durians and mangosteens are important products of the eastern provinces of Thailand. Grown widely in Southeast Asia, these fruits have economic value due to their excellent flavor and richness in nutrients. Their life cycles begin in December and January when both plants flower. It takes another month for them to bloom and four additional months before they are mature enough to be harvested. The life cycles are summarized in Figure 1.It is well known that drought induces tropical trees to flower. The rainy season ends in October. A period of approximately one month with little rain is observed before the soil and air are dry enough, placing the flowering date in December. In some years, however, the heavy rainfall postpones the flowering date to as late as January, and the still immature products that are not yet harvested will be at risk from the moisture once the next rainy season starts [2]. Our goal is to devise a simple forecasting model to answer one of fruit farmers' main concerns: how wet or how dry will the weather conditions be at the end of the year? This model can facilitate a more efficient crop water management. Figure 2 shows eastern Thailand. The studied area is bordered by the sea to the southwest. To the southeast is the Kravanh mountain of Cambodia. The mountain range continues into Thailand to the middle of the studied area and there is called the Kitchakut Mountain. The Asian monsoon regulates the rainfall within the area, and is a global phenomenon that spans a vast area from the Arabian Sea to the western North Pacific and Korean Peninsula [17]. Best understood as the seasonal and directional changes in the upper and lower wind field, the Asian monsoon is a part of the interactive system between the oceans and the atmosphere [12, $13,15]$.

Over Thailand this monsoon system consists of two types of wind: the south-westerly and the northeasterly. The southwesterly brings moisture from the Indian ocean, and the northwesterly coldness and dryness from inland China. The onset of the rainy season 
refers to the change in wind direction from the surface northeasterly to the southwesterly and vice versa in the upper troposphere. The onset over Indochina occurs, on average, on May 9th, with a standard devia- tion of 12 days, and is characterized by the intensification and northward extension of the tropical convection from Sumatra, coinciding with the weakening of the midlatitude westerly over south Asia [18].

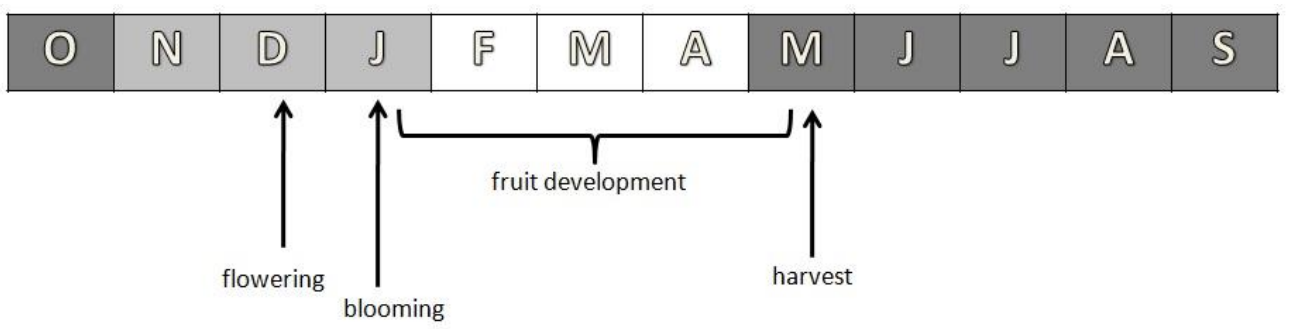

Figure 1. The scheme of the crop cycle. The light shade represents the three-month dry season (known as the winter in Thailand), white represents the three-month summer, and the dark shade represents the six-month rainy season.

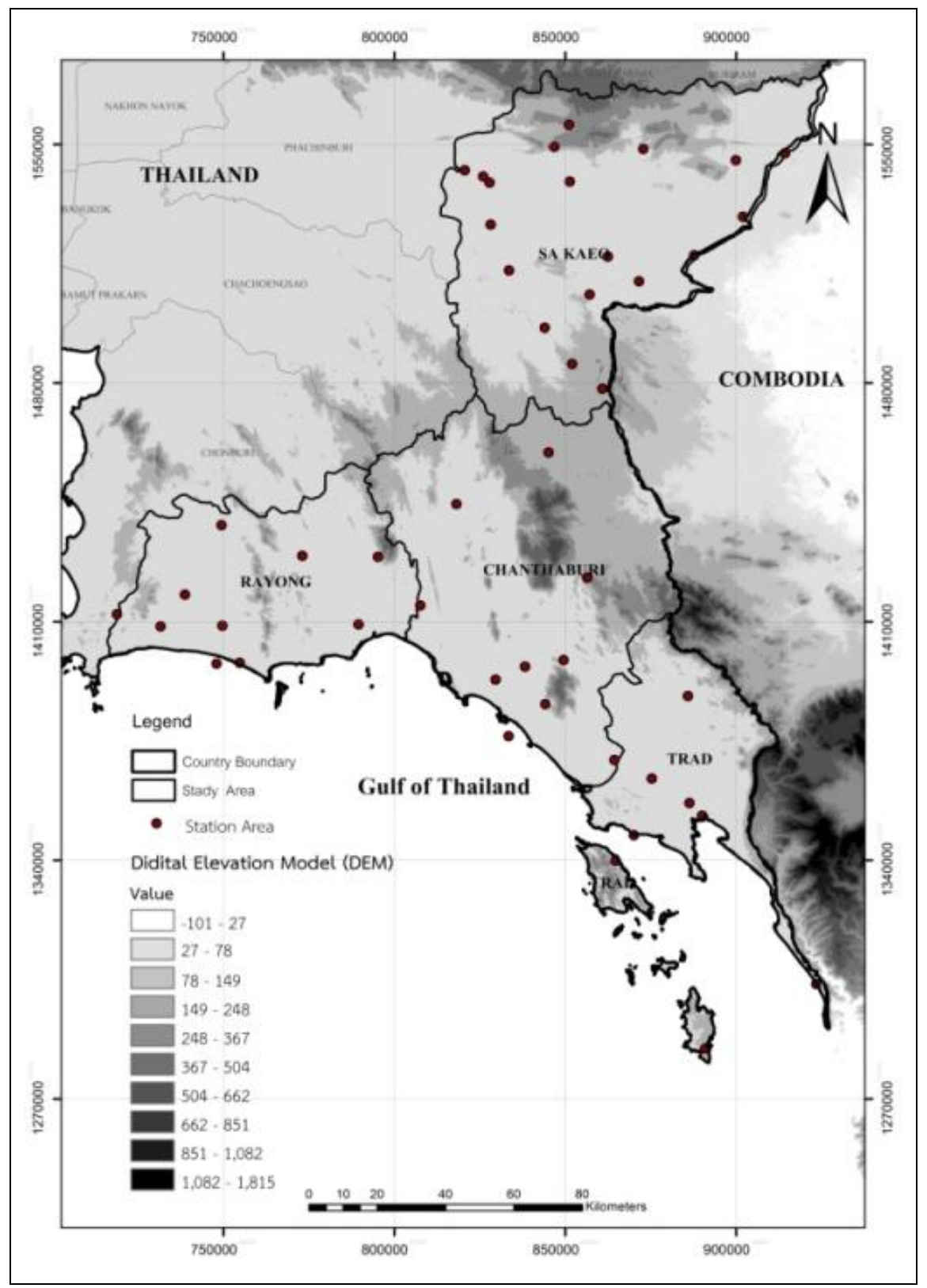

Figure 2. A topographic map of the area studied with the sites of the rain stations 
The date can be identified by looking at synoptic wind fields [15], long wave reflectivity signals [8], or in situ measurements [1, 5] as in our own method.

We aim to use the onset date of the southwesterly monsoon to determine the withdrawal - a late withdrawal indicates wet conditions at the end of the year, and an early withdrawal indicates dry conditions. The onset signals the beginning of the rainy season and is among the first factors that we empirically determine about the monsoon each year. It is a useful parameter because farmers are naturally aware of the beginning of the rainy season without the need of intricate instrument. There are other regions in which the onset is similarly used as a prognostic tool in regional water management. Marteau [14] and Sultana [3], for example, analyze the sowing strategy of farmers in the Sudano-Sahelian zone of western Africa in regard to the onset of the rainy season. Sivakumar [11] used the onset date of the African Monsoon to predict the length of the rainy season in western Africa and devise the most effective agricultural scheme.

Table 1. A Summary of the data used in this study.

\begin{tabular}{|c|c|c|c|c|c|}
\hline Province & Years & $\begin{array}{c}\text { The number } \\
\text { of stations }\end{array}$ & $\begin{array}{c}\text { Average daily } \\
\text { rainfall in } \\
\mathbf{m m} .\end{array}$ & $\begin{array}{c}\text { Standard } \\
\text { deviation in } \\
\text { mm. }\end{array}$ & X in mm. \\
\hline Chantaburi & $1951-2013$ & 8 & 7.5 & 6.64 & 3.78 \\
Trat & $1951-2013$ & 8 & 11.31 & 10.37 & 6.51 \\
Sa Kaeo & $1951-2013$ & 10 & 3.99 & 2.86 & 2.37 \\
Rayong & $1967-2013$ & 21 & 3.80 & 3.19 & 3.22 \\
\hline
\end{tabular}

Compared to the onset, the withdrawal or the end of the rainy season is less studied and its nature still contested. It refers to the change in wind direction from the surface southeasterly to the northwesterly, and is found to be gradual in Indochina, as characterized by the reduction of rainfall intensity, the decay of the anticyclonic circulation over the Tibetan Plateau, and the reappearance of the upper- level westerly jet stream [8]. The withdrawal date varies from region to region, depending on localized and orographic influences $[4,6]$, but occurs near October in Thailand. An early onset was found to be associated with an early withdrawal in Kerala, India [13], but with a late withdrawal in the Amazon, [7].

Our goal is to devise a simple forecasting model to answer one of fruit farmers' main concerns: how wet or how dry will the weather conditions be at the end of the year? We establish the statistical relationship between the onset and the withdrawal date. The relationship will be empirical. It has a practical linkage to the best strategy for the regional water management. Section 2 details the basic information of the rain data used in this study. Section 3 shows the result of our analysis and how to adapt it to our forecasting model. Section 4 discusses the mechanisms behind the result and proposes studies for further improvement.

\section{Data and methodology}

The research area comprises the eastern provinces of Thailand, specifically Chantaburi, Trat, Rayong, and Sa Kaeo. The rainfall data is taken from the rain stations of the Thai Meteorological Department as shown in Figure 2. Figure 3 shows the distribution of the average annual rainfall. The daily rainfall data are summarized in Table 1. Trat is the rainiest province due to its closest proximity to the Kravanh Mountains. The southwesterly monsoon brings in moisture, and the area in front of the mountain receives the most precipitation. The rain lessens farther away from the mountain in Chantaburi and Rayong. Sa Kaeo also receives a small amount of rainfall due to its location behind the Kitchakut Mountain.

Figure 4 shows the amount of daily rainfall in $\mathrm{mm}$ in May (a) and October (b) of 1980. May is the beginning of the rainy season, 
and as the month progresses, the daily rainfall increases. An opposite trend happens in October, the end of the season. These two plots, however, illustrate a strong daily fluctuation without any clear indication of the exact date for the onset and the withdrawal. Certain objective criteria are necessary to identify those dates; ours are adapted from [18].

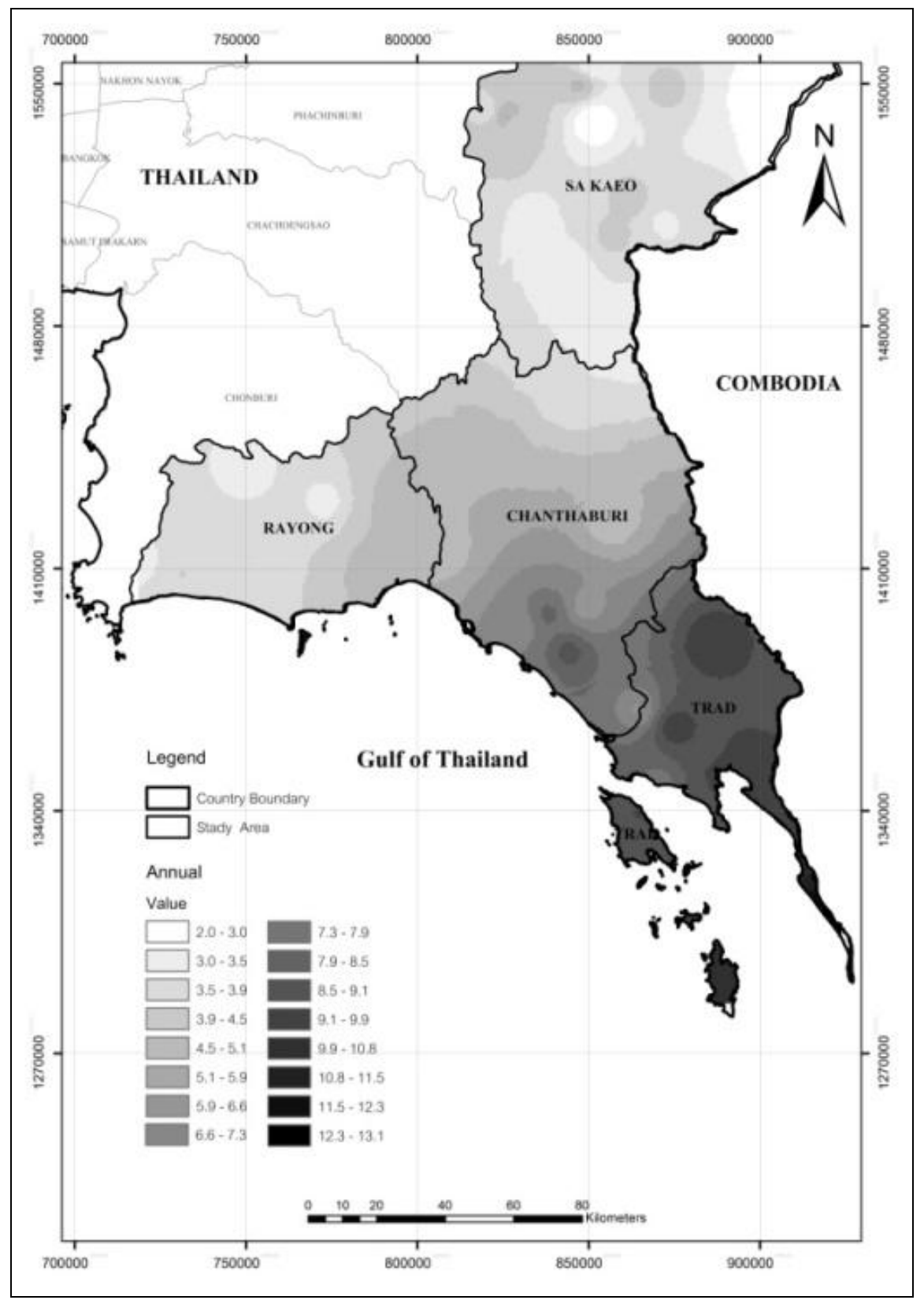

Figure 3: The distribution of the annual rainfall (mm).

The area is the wettest in the southeast, and drier in the north and the west.

Briefly summarized, we search for the onset on the first date after which the possibility of rainfall drastically increases; for the withdrawal, the criteria are reversed. This possibility is calculated from the number of days the rain exceeds certain thresholds, $\mathrm{x}$, summarized in Table 1 . How we define $\mathrm{x}$ will be explained in detail in the appendix. Based on these two criteria, the onset in Figure 4 is identified as May 17th, and the withdrawal October 7th. 


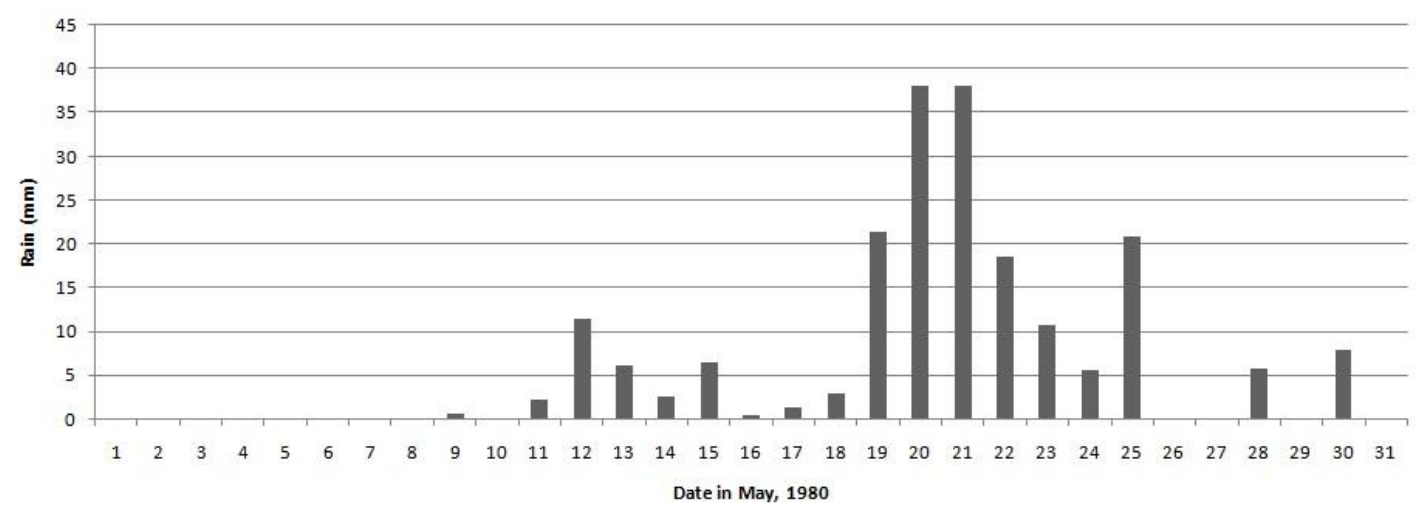

Figure 4a: The rainfall in May, 1980, in millimeters.

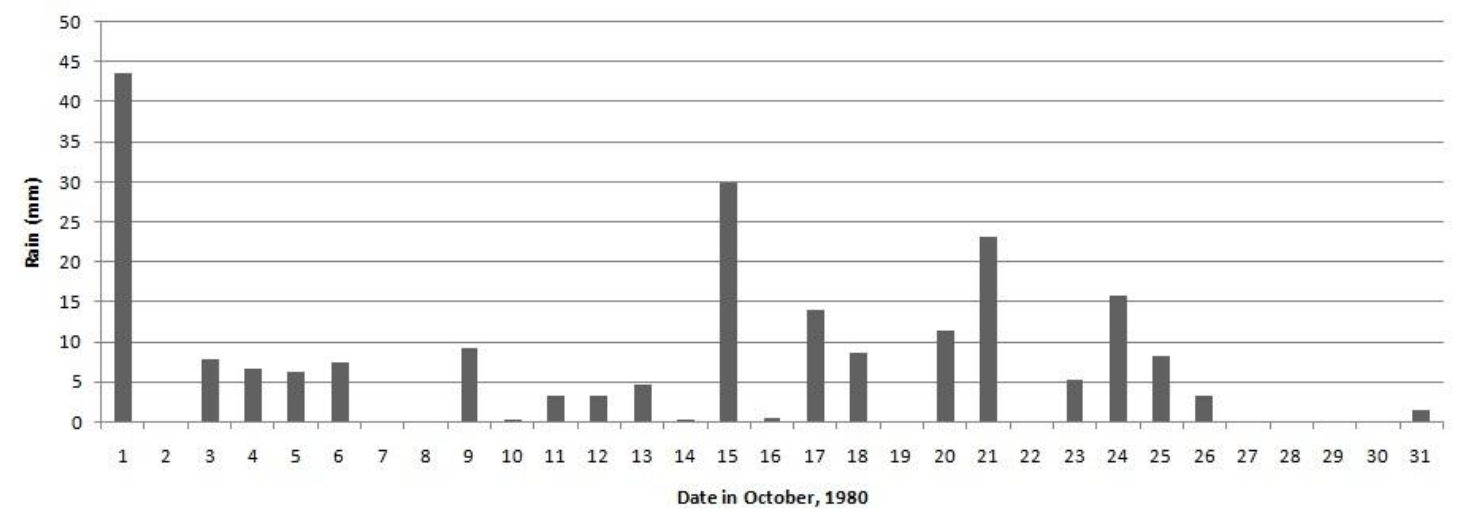

Figure 4b: The rainfall in October, 1980, in millimeters.

For these dates to be meaningful, we expect them to bear some linkage to the average rainfall. We compute the onset and withdrawal date for each province for each year, and plot the results against the average rainfall in April and May (Figure 5a) and in September and October (Figure 5b). The average rainfall is normalized, so that we can compare them across provinces. A year in which the rainy season comes late, as expected, has a tendency toward a lower average rainfall in April and May, while a year in which the rainy season leaves late has a tendency toward a higher average rainfall in October and November. This is especially robust for the lower bound as indicated by the dashed line. The onset and withdrawal, however, give no indication of the maximum rain intensity. The rain may come late, but it can still fall hard. The upper bounds do not behave in a similarly characteristic manner, although the trends are still present.
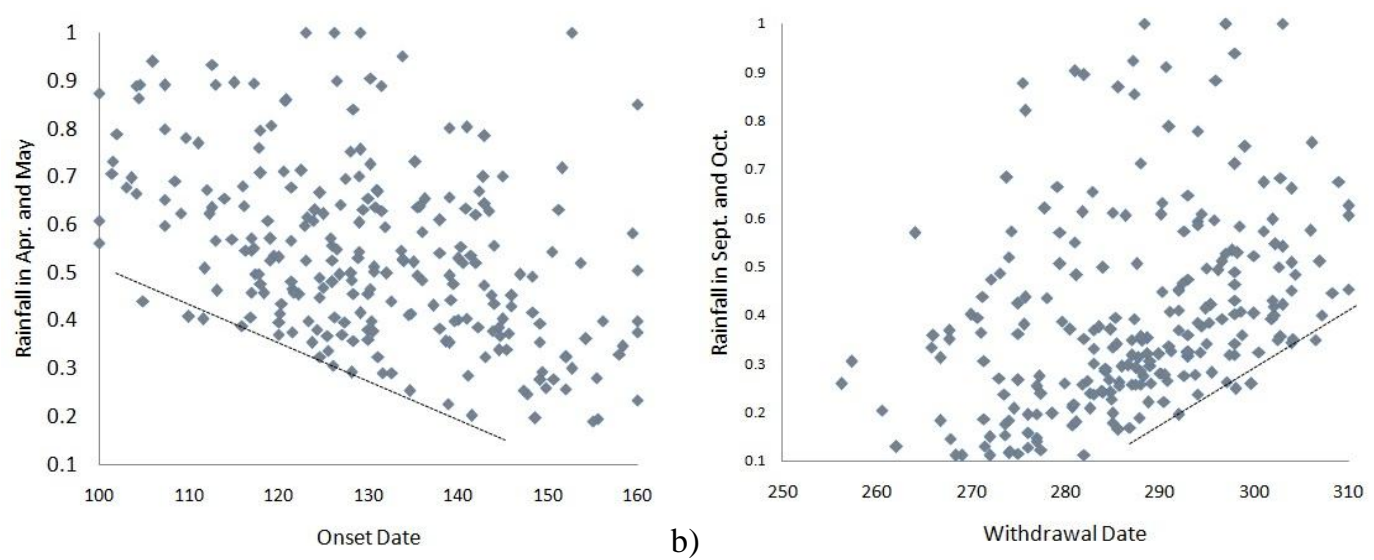

Figure 5: The scatter plots between the onset and withdrawal date versus the average rain intensity in April and May (a) and October and November (b), respectively. The dotted lines approximate the tendencies of the minimum rain 


\section{Results}

Figure 6 shows the distribution of the onset and withdrawal dates across the area. Dark shading designates a wet area with an early onset and a late withdrawal. The location with the earliest onset and latest withdrawal is Trat. The onset becomes later, and the withdrawal earlier as one moves away from the Kravanh Mountains. Sa Kaew, behind the Kitchakut Mountain, has distinctively late onsets and early withdrawals. This is similar to the distribution of the average rain intensity in Figure 3. Note that we ignore a measurement from one station behind the Kitchakut mountain since it gives out an uncharacteristically late withdrawal. This might be due to its having so little rainfall that our method for detecting the withdrawal does not work well. Another feature that sets Figure 6 apart from Figure 3 is Rayong, the eastern province, has an uncharacteristically long rainy season considered how dry the area is. The orographic effect of the Kitchakut mountain in the middle of the studied area possibly brings in an early rainfall.

This relationship between the two parameters can also be observed in a boxplot in Figure 7. The data are partitioned into four groups based on the onsets. The box for each group shows the latest and earliest withdrawal, the twenty-fifth, fiftieth and seventyfifth percentile, and the mean is shown with a diamond marker. The plot exhibits a decreasing trend in the percentiles, the extremities, and the average value. An area with a late onset has, on average, an early withdrawal, while the opposite is true. The slope of the linear regression between the average onset and withdrawal dates is -0.32 \pm 0.08 . Since the local rainfall is under the influence of the Monsoon and the geography, the rainier areas closer to the mountain have longer seasons with early onsets and late withdrawals.
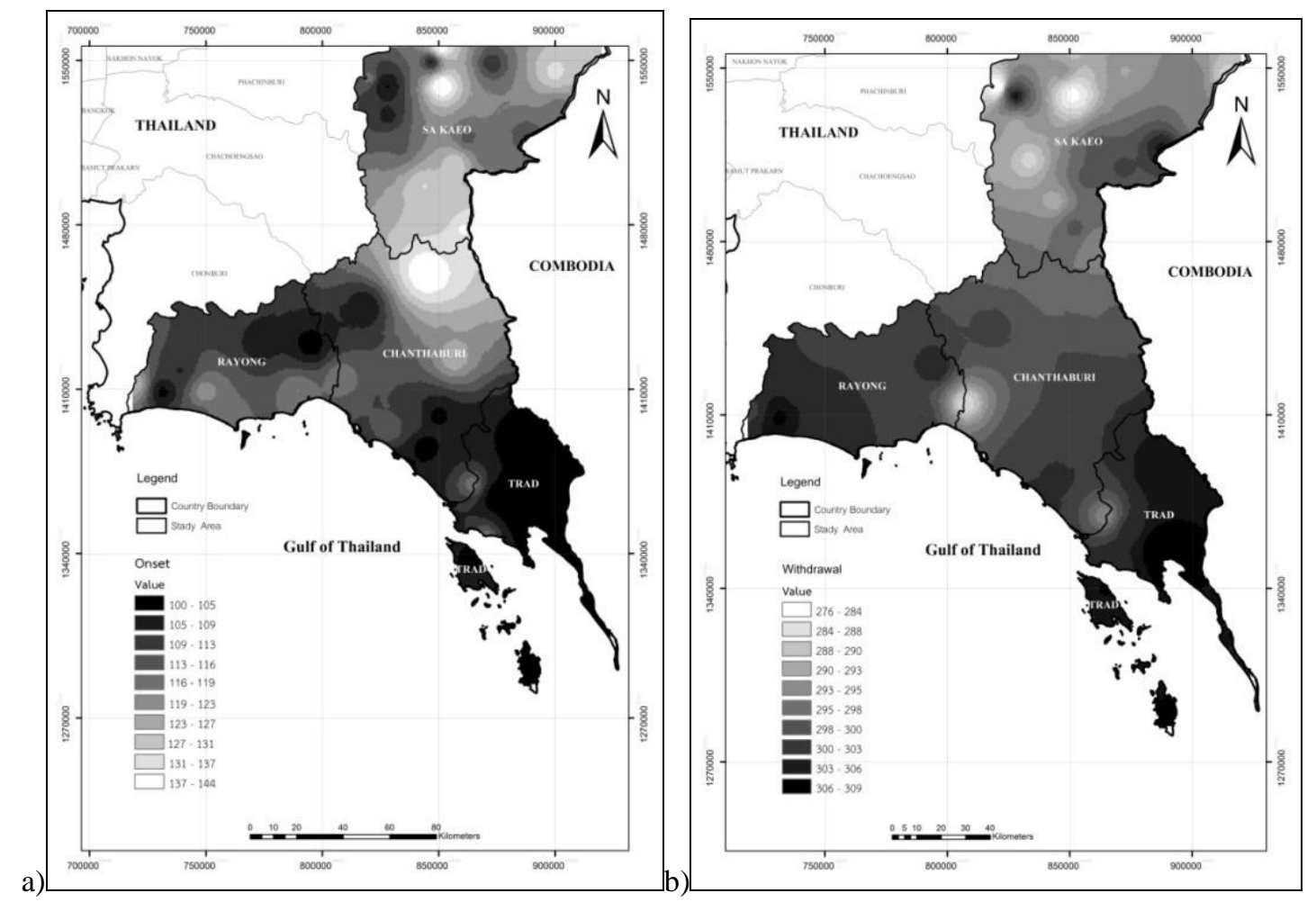

Figure 6: The distribution of the onset dates (a) and withdrawal dates (b) in Julian date in the area studied. The Kitchakut mountain in the center apparently divides the area into two zones. The southwest has an early onset and a late withdrawal, and the northeast a late onset and an early withdrawal. 
Our main concern, however, is not the spatial but the temporal correlation. Knowing how the withdrawal date varies from year to year can help the fruit farmers. Figure 8 shows for each year a boxplot between the distribution of withdrawal dates and the onset date averaged across the provinces. In a given year in which the onset comes late -- for example, after the Julian date 143 -- the withdrawal is, on average, approximately ten days earlier than in a year in which the onset comes early -- for example, before the Julian date 124. The slope of the linear regression between the average onset and withdrawal dates is -0.36 \pm 0.04 .

When and where the rainy season is short, it has both a late onset and an early withdrawal. This result is worth mentioning since in some monsoonal regions such as in Africa, the onset bears little relationship to the withdrawal [11]. In India they bear a positive relation [13], and in the Amazon a negative one [7] like in this study.

\section{Discussion and conclusion}

The timing of the withdrawal appears to be negatively correlated with the timing of the onset nearly six months earlier. What could be the reason behind this? The oceans interacts with the atmosphere and arising from that complexity is the phenomenon known as the Asian Monsoon, which in turn governs the rainy seasons in the area. While the entire range of the interaction is yet to be fully understood, scientists have learned to partially quantify it through the changing sea surface temperature. The Southern Oscillation refers to variations in the temperature of the tropical eastern Pacific Ocean with warming known as El Nino and cooling known as La Nina.

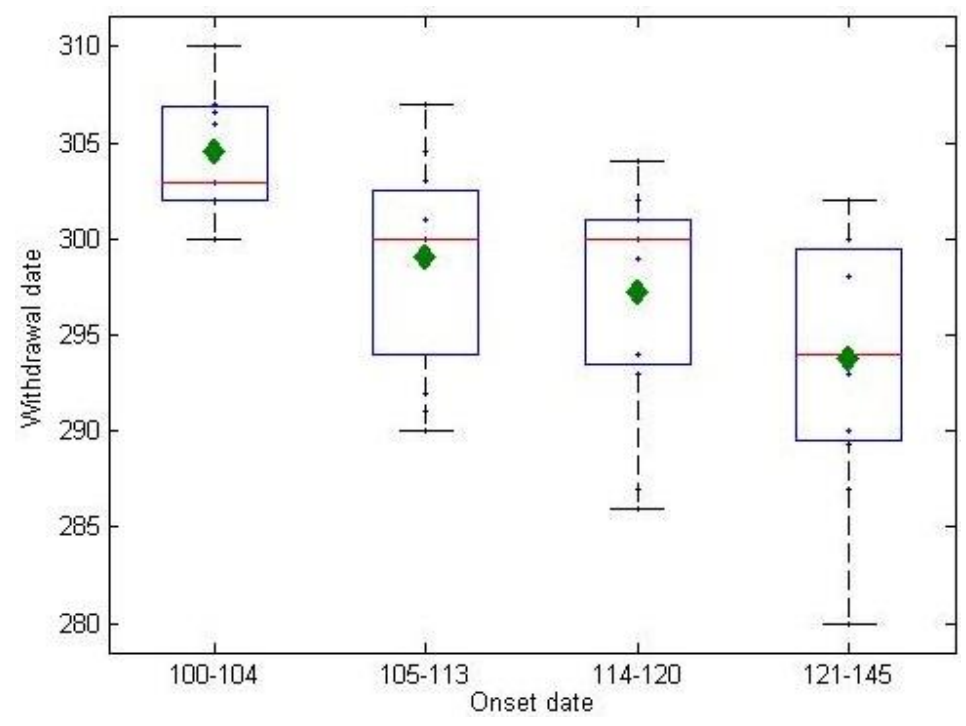

Figure 7: A boxplot showing the onset date on the $\mathrm{X}$-axis and the withdrawal date on the $\mathrm{Y}$-axis based on various stations across the area. A location with an early onset, on average, appears to have a late withdrawal, and the opposite is true.

During an El Nino Year, the westerlies and the Walker circulation weaken. Moisture is belatedly transported into Indochina, resulting in late onset, early withdrawal and abated rainfall. Reverse mechanisms occur during a La Nina year, when the rainfall increases and the onset occurs early $[4,9$, $10,12,16]$. Our conclusion here is similar to Marengo [7] which analyzes the onset and the withdrawal date of the rainy season in the Amazon along with the SST of the
Pacific and the Atlantic. When the SST of the western Pacific is higher than average and of the Eastern Atlantic lower, the onset of the rainy season is delayed and the withdrawal hastened.

We aim to devise a forecasting strategy to accommodate the fruit farmers who are primarily concerned with the weather conditions at the beginning of their crops' life cycles. We only present parameters that 
are intuitive and are relevant to a layperson, such as the beginning and the end of the rainy season. The strategy estimates the end of the rainy season using the statistical correlation between the onset and withdrawal; in a year with an early onset, the withdrawal will come late, and the opposite is true. While the rainy season in this area generally ends around October 9th, on the one hand, if the onset comes after
May 29th, the withdrawal may be 8 days on average earlier than the general date; on the other hand, if the onset comes before April 27 th, the withdrawal is delayed on average by seven days. Such years present risks to the farmers who, once aware that their products may be harmed, can adjust their cropping strategy, for example, by using chemicals that shorten the maturing time or prevent the buds from turning into leaves.

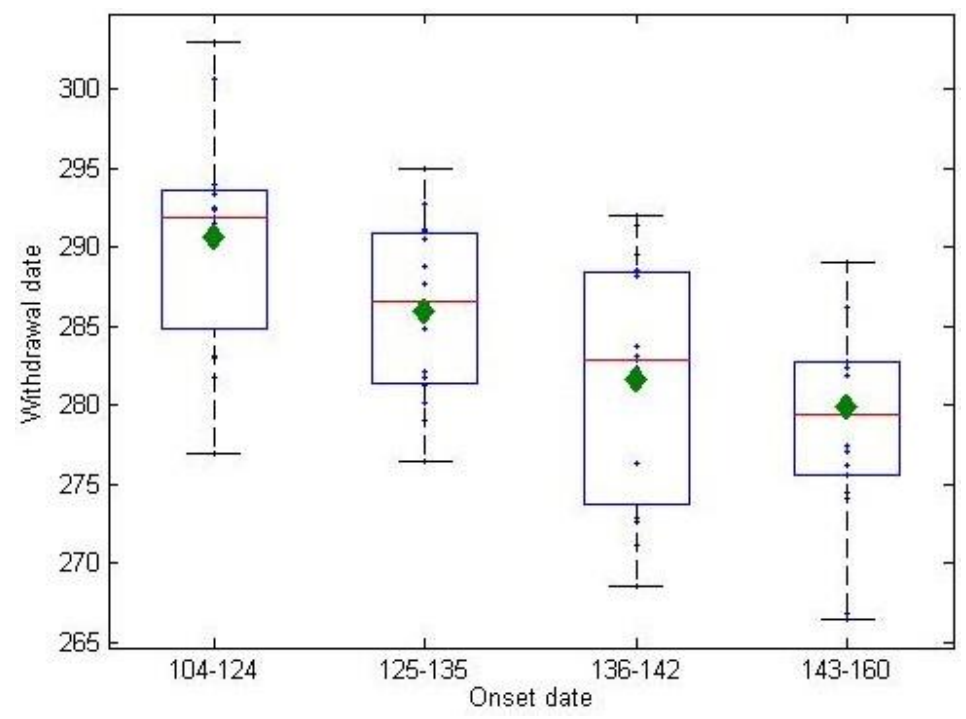

Figure 8: A boxplot showing the onset date on the $\mathrm{X}$-axis and the withdrawal date on the $\mathrm{Y}$-axis based on various stations across different years. A year with an early onset, on average, appears to have a late withdrawal, and the opposite is true.

For a future study, we aim to approach this same relationship between the onset and the withdrawal using different methods such as examining the wind field or radar data. Does this relationship occur anywhere else in Indochina, and what does it tell us about the nature of the Monsoon? We also aim to establish a more robust connection between the withdrawal and flowering dates of fruit plants.

We finally would like to thank Kasetsart University Research and Development Institute for the funding of this project.

\section{Appendix: The criteria for determining the onset and the withdrawal}

Our criteria are adapted from Zhang [18]. The onset is the date after which the possibility of a rainy day drastically increases, and the withdrawal the date after which the possibility of a rainy day decreases.

First, we define a rainy day as one when the rainfall exceeds a certain threshold, $x$. This value must be adjusted to suit different locations. In Chantaburi, the average rain intensity is $15.11 \mathrm{~mm}$ between June 18th and August 25th. The two bracketing dates are chosen such that the former is assuredly later than the onset and the latter is earlier than the withdrawal. The rain intensity between the two is hence the true average rainfall of the monsoon season. We then take $\mathrm{x}$ to be one third of this value; the day is categorized as rainy if its rainfall exceeds one third of its average value. The same applies for other provinces. The values of $\mathrm{x}$ are summarized in the last column of Table 1.

We define the onset as the first date between April 10th and June 8th when: 
1. The rainfall is greater than a certain threshold, $\mathrm{x}$ mm.

2. The rainfall on each of the two consecutive days afterward exceed $\mathrm{x} \mathrm{mm}$.

3. Within nineteen days afterward, at least a certain number of days -- y -- have rainfall greater than $\mathrm{x} \mathrm{mm}$.

If $y$ is too large, the algorithm will identify the onset as near the end of the searching period. If $\mathrm{y}$ is too small, the algorithm might catch an early summer storm instead of the true beginning of the season. For each year, we vary y from 5 to 15 days and use the average value of the resulting onsets for all cases.

The withdrawal date is the last date between September 5st and November 5st. The criteria for the withdrawal are the same, but are reversed. when:

1. The rainfall is greater than $\mathrm{xmm}$.

2. The rainfall exceeds a certain threshold, $x$ $\mathrm{mm}$, on the two consecutive days before the date.

3. Within nineteen days before the date, at least a certain number of days -- $y$-- have a rainfall greater than $\mathrm{x} \mathrm{mm}$.

We perform a sensitivity test, checking whether the different values of $\mathrm{x}$ and $\mathrm{y}$ will significantly affect our results. The relationship between the onset and the withdrawal appears to be conclusive provided that the two parameters are within certain ranges.

\section{References}

[1] A. Limsakul \& S. Limjirakan \& B. Suttamanuswong. Asian summer Monsoon and its associated rainfall variability in Thailand. Environment Asia, vol. 3, pp 79-89, 2010.

[2] A. Srisaart. Durian, mangosteen, and rambutan: cash crops for the AEC. Naka Intermedia Ltd., Samutsakorn, Thailand, 2013.

[3] B. Sultana \& C. Baronb \& M. Dingkuhnb \& B. Sarrc \& S. Janicota. Agricultural impacts of large-scale variability of the west african monsoon. Agric. For. Meteorol., vol. 128, pp 93-110, 2005.

[4] B. Wang \& L. Ho. Rainy season of the Asian Pacific summer Monsoon. J. Climate, vol. 15, pp 386-398, 2001.

[5] C. S. Chen \& Y. L. Chen \& C. L. Liu \& P. L. Lin \& W. C. Chen. Statistics of heavy rainfall occurrences in Taiwan. Wea. Forecasting, vol. 22, pp 981-1002, 2007.

[6] E. M. Mugalavai \& E. C. Kipkorir \& D. Raes \& M. S. Rao. Analysis of rainfall onset, cessation and length of growing season for western Kenya. Agric. For. Meteorol., vol. 148, pp 1123-1135, 2008.

[7] J. A. Marengo \& B. Liebmann \& V. E. Kousky \& N. P. Filizola \& I. C. Wainer. Onset and end of the rainy season in the brazilian amazon basin. J. Climate, vol. 14, pp 833-852, 2001.

[8] J. Fasullo \& P. J. Webster. A hydrological definition of Indian Monsoon onset and withdrawal. J. Climate, vol. 16, pp 3200-3211, 2003.

[9] J. Ju \& J. Slingo. The asian summer monsoon and ENSO. Q. J. R. Meteorol. Soc., vol. 121, pp 1133-1168, 1995.

[10] M. K. Soman \& J. Slingo. Sensitivity of the asian summer monsoon to aspects of seasurface-temperature anomalies in the tropical pacific ocean. Q. J. R. Meteorol. Soc., vol. 123, pp 309-336, 1997.

[11] M. V. K. Sivakumar. Predicting rainy season potential from the onset of rains in southern Sahelian and Sudanian climatic zones of west Africa. Agric. For. Meteorol., vol. 42, pp 295-305, 1988. 
[12] N. Singhrattna \& B. Rajagopalan \& K. K. Kumar \& M. Clark. Interannual and interdecadal variability of Thailand summer Monsoon season. J. Climate, vol. 18, pp 1697-1708, 2005.

[13] P. V. Joseph \& J. K. Eischeid \& R. J. Pyle. Interannual variability of the onset of the indian summer Monsoon and its association with atmospheric features, El Nino, and sea surface temperature anomalies. J. Climate, vol. 7, pp 81-105, 1994.

[14] R. Marteau \& B. Sultan \& V. Moron \& A. Alhassane \& C. Baron \& S. B. Traore. The onset of the rainy season and farmers' sowing strategy for pearl millet cultivation in southwest niger. Agric. For. Meteorol., vol. 151, pp 1356-1369, 2011.

[15] R. Wu \& B. Wang. Interannual variability of summer Monsoon onset over the western north Pacific and the underlying processes. J. Climate, vol. 13, pp 2483-2501, 2000.

[16] S. Yang \& K.-M. Lau. Influences of sea surface temperature and ground wetness of asian summer monsoon. J. Climate, vol. 11, pp 3230-3246, 1998.

[17] V. Moron \& A. W. Robertson \& R. Boer. Spatical coherence and seasonal predictability of Monsoon onset over Indonesia. J. Climate, vol. 22, pp 840-850, 2009.

[18] Y. Zhang \& T. Li, B. Wang \& G. Wu. Onset of the summer Monsoon over the Indochina Peninsula: climatology and interannual variations. J. Climate, vol. 15, pp 3206-3221, 2002. 
